\title{
ANÁLISIS
}

\section{Trasfondo histórico del envío del embajador Hasekura a España y la Nueva España en 1614}

DOI: $10.32870 /$ mycp.v3i7.456

Koichiro Yaginuma ${ }^{1,2}$

\section{Resumen}

En la época de las "grandes navegaciones" realizadas por las potencias ibéricas de España y Portugal, se enlazaron los mundos del Oriente y el Occidente. Poco después, una vez establecida su hegemonía en el Océano Pacífico, la Co-

Artículo recibido el 10 de marzo de 2014 y dictaminado el 13 de marzo de 2014.

1. Profesor de la Sección de la lengua española, Departamento de Estudios Iberoamericanos, Facultad de Lenguas Extranjeras, de la Universidad de Estudios Internacionales de Kanda (vicerrector, Kanda University of International Studies, KUIS). Titulado en la Maestría de Historia Contemporánea de México, de la Facultad de Filosofía y Letras de la Universidad Nacional Autónoma de México (UNAM). Correo electrónico: mexsol1321@da3.so-net.ne.jp

2. El 24 de septiembre de 2009 se celebraron, tanto en el Instituto Cervantes de Tokio como en el "Espacio Mexicano" de la Embajada de México en Tokio, actos conmemorativos por "400 años de amistad de Onjuku: Cuarto Centenario de Intercambios entre Japón, México y España". Igualmente, del 6 al 8 de octubre de 2010, en la Universidad de Guadalajara se realizó el "Festival Japonés: 400 Aniversario México-Japón", para celebrar 400 años de vínculos entre Japón y México. Estas actividades han sido un gran estímulo a la investigación sobre el vínculo histórico entre Japón y el mundo hispano. Aprovechando esta ocasión, quisiera expresar mi profundo y sincero agradecimiento por sus valiosos comentarios al doctor Omar Martínez Legorreta, de El Colegio Mexiquense. En particular le estoy sumamente agradecido al profesor Daisuke Kishi, mi amigo personal y colega, así como a la doctora Melba Falck Reyes, de la Universidad de Guadalajara, por sus comentarios y cooperación, y sobre todo por su amable invitación al "Seminario Internacional: Navegando el Pacífico. Japoneses, chinos y filipinos en la Nueva España. Siglos XVI y XVII", celebrado del 7 al 8 de noviembre de 2013 en Guadalajara, México. Y finalmente también aprecio la ayuda de mi colega mexicana, doctora Silvia Lidia González, de la Universidad de Estudios Internacionales de Kanda (KUIS). 
rona española realizó su avance hasta el territorio de Japón y empezó a tener contactos directos con ese país en la época de los poderosos gobernantes de Oda Nobunaga y de Toyotomi Hideyoshi. A través de la predicación y del comercio con los países ibéricos de España y Portugal, llamado "Nanban-boeki", se divulgó en Japón la "cultura Nanban" y su influencia fue definitiva en el llamado "siglo cristiano" en la historia de Japón, época en que este país pasó de la Edad Media a la Moderna.

Así empezaron las relaciones diplomáticas directas y dinámicas entre Japón, la Nueva España y España. En particular, el gobierno del shogunato de Tokugawa Ieyasu emprendió la gran tarea de abrir negociaciones con el gobierno español de Manila, Filipinas, así como con el virrey de la Nueva España y con la Corona española, intercambiando misiones o embajadas.

Por otra parte, en ese momento los holandeses e ingleses se aproximaron al shogunato sin tocar el tema religioso, en una maniobra política dirigida contra los españoles. Posteriormente, en dichas circunstancias el señor feudal "Daimyo" Date Masamune de Sendai, bajo la autorización del shogunato, también con la colaboración de fray Luis Sotelo, envió la embajada Hasekura Tsunenaga a la Nueva España y España, así como al Vaticano para entrevistarse con el papa Paulo V, con el objeto de concretar las relaciones amistosas y el comercio con ellos.

Palabras clave: Tratado de Tordesillas, hegemonía en el Océano Pacífico de la Corona española, comercio de Nanban-boeki, cristianismo en Japón, capitulaciones de Vivero.

\section{Abstract (Historical Background in the Mission of Hasekura Embassy to Spain and New Spain in 1614)}

At the time of the "great navigations" promoted by the Iberian powers of Spain and Portugal, East and West hemispheres became linked. Shortly after the consolidation of its hegemony in the Pacific Ocean, the Spanish Crown began contacts with Japan.

Religious principles and trade with European countries (called "NanbanBoeki") had a great influence in the transition of Japan from the Middle Age to a Modern Age.

Thus began the diplomatic relations between Japan, Spain and the colony so called New Spain. The government of Tokugawa Ieyasu shogunate under- 
took the great task of opening negotiations with the Spanish government in Manila, Philippines, as well as the authorities in New Spain.

Moreover, at that time, Dutch and English delegations approached the shogunate in a political tactic directed against the Spanish power. Later, in such circumstances, the feudal lord "Daimyo" Date Masamune of Sendai, under the authority of the shogunate, with the collaboration of fray Luis Sotelo, sent an embassy in charge of Hasekura Tsunenaga to New Spain, Spain and the Vatican to meet with Pope Paul V, in order to strengthen friendly and commercial relations.

Keywords: Treaty of Tordesillas, hegemony in the Pacific Ocean of the Spanish Crown, Nanban trade, cristianity, capitulations of Vivero.

\section{Introducción}

Los contactos entre Japón, España y la llamada Nueva España iniciaron con el episodio del histórico rescate del galeón novohispano "San Francisco", en su ruta hacia Acapulco, que naufragó el 30 de septiembre de 1609 frente a las costas de Onjuku, en la Península de Boso, al sur de Edo, que actualmente es Tokio, la capital japonesa.

A bordo del galeón iban don Rodrigo de Vivero y Velasco, ${ }^{3}$ ex gobernador interino de la Nueva España en Manila, Filipinas, y 317 tripulantes novohispanos que fueron rescatados y abrigados por la población de Onjuku. Igualmente ofreció gran ayuda el gobernante de la época, el shogun Tokugawa Ieyasu, ${ }^{4}$ quien proporcionó la nave "San Buenaventura", construida por William

3. Rodrigo de Vivero y Aberruza (1564-1636), primer conde del Valle de Orizaba y encomendero de Tecamachalco, Puebla, nació en México en el año 1564, hijo de don Rodrigo de Vivero y Velasco y doña Melchora de Aberruza. Don Rodrigo hijo se crió entre los hijos de encomenderos, colonos y conquistadores hasta sus 12 años (1576), cuando su padre lo envió a España para ser menino de doña Ana de Austria, esposa de Felipe II. Después de volver a la Nueva España, en el año 1595, se le expidió nombramiento de alcaide, capitán y castellano del puerto de San Juan de Ulúa, Veracruz. En 1599 fue nombrado alcalde mayor del pueblo y minas de Taxco, y unos años después lo nombraron capitán general de la Nueva Vizcaya. Su conocimiento de la frontera había hecho de Vivero el hombre más indicado para llevar la expansión colonial de España en aquellos difíciles territorios. (Véanse, Ballesteros Gaibrois, M. (1947), 'Papeles de Indias I, Edición, prólogo y notas, Rodrigo de Vivero: su vida y su obra', y Documentos inéditos para la historia de España, tomo V, Madrid, España, p. XXIII.)

4. Tokugawa Ieyasu (1543-1616) nació en la provincia de Mikawa. Fue el fundador y primer shogun del shogunato de Tokugawa, régimen que gobernaría desde la Batalla de Sekigajara en 1600 hasta la “Restauración Meiji” en 1868. En 1603, después de dicha batalla, Tokugawa Ieyasu recibió el título oficial de shogun. Posteriormente también le llamaban con otro título de "Ogoshosama", es decir el shogun enclaustrado. 
Adams, en la que el 1 de agosto de 1610 los novohispanos salieron de Uraga, cerca de la capital Edo, y lograron llegar el 27 de octubre a Matanchén, en las costas de Nayarit, y unos días después llegaron a Acapulco, México.

A partir de dicho acontecimiento, el virrey de la Nueva España, Luis de Velasco, decidió organizar una nueva legación del general Sebastián Vizcaíno ${ }^{5}$ para acudir ante Tokugawa Ieyasu y su hijo el shogun Hidetada, ${ }^{6}$ con el fin de expresar su agradecimiento por el trato ofrecido a su sobrino Rodrigo de Vivero y Velasco; además, buscaban entablar relaciones directas con el gobierno del país del Sol Naciente. Así, a bordo del navío "San Francisco" esta expedición inició el 22 de marzo de 1611 y llegó al puerto de Uraga el 10 de junio del mismo año. El general Vizcaíno, en calidad de embajador, tenía también la orden oficial de explorar las costas japonesas y descubrir las legendarias islas "Rica de Oro" y "Rica de Plata".

Aprovechando la audiencia con Ieyasu, su hijo el shogun Hidetada y otros altos funcionarios del shogunato, el general Vizcaíno les solicitó permiso para demarcar y sondear las costas japonesas para los barcos novohispanos de Manila, insistiendo en la expulsión de los holandeses, quienes se habían rebelado contra España y se creía que sus posibles ataques ponían en peligro la seguridad de la ruta Manila-Japón; posteriormente emprendió la búsqueda de las islas Rica de Oro y Rica de Plata. Sin embargo, Vizcaíno fracasó en su empresa y se vio obligado a regresar a Suruga, Japón. Además, no pudo conseguir ayuda alguna de parte del shogunato, así que resultaron estériles todos sus esfuerzos y cayó enfermo. En estas circunstancias, Vizcaíno recibió una propuesta del proyecto que había formulado el principado de Sendai, bajo el mando de Date Masamune, ${ }^{7}$ con la cooperación del religioso español fray

5. Sebastián Vizcaíno nació en 1551? en Huelva, España. Después de haber participado en la invasión a Portugal, en 1583 se trasladó a la Nueva España y desde 1586 hasta 1589 se dedicó al comercio y servicio en la milicia en Manila, Filipinas. En 1602, Gaspar de Zúñiga, el virrey de la Nueva España, le nombró general para dirigir la exploración de la costa de California en busca de los puertos de refugio seguros para el galeón de Manila. En 1604 fue nombrado general de los galeones de Manila y en 1607 recibió la encomienda de la provincia de Ávalos en la Nueva España. En 1611 fue nombrado por Felipe III embajador ante el shogunato de Tokugawa y general de la expedición de las míticas islas "Rica de Oro y de Plata" (Murakami Naojiro, 1941: III-IV).

6. Tokugawa Hidetada (1579-1632), hijo de Tokugawa Ieyasu y el segundo shogun Tokugawa, gobernó desde 1605 hasta su abdicación en 1623.

7. Date Masamune (1567-1636), por la falta de un ojo llamado comúnmente "Dokuganryu" (Dragón de un solo ojo), sucedió a su padre a la edad de 18 años. Después de la muerte de Hideyoshi, el poderoso gobernante posterior a Oda Nobunaga, Masamaune le brindó su apoyo a Tokugawa Ieyasu. Entonces mostró simpatía por los misioneros cristianos. Además de que les permitía 
Luis Sotelo. La propuesta era enviar una representación para entrevistarse con el virrey de la Nueva España, el rey de España y con el papa. El Daimyo Date Masamune, llamado también el "Rey de Ohsyu", simpatizaba con la religión cristiana y se mostró interesado en facilitar un puerto para las naos de Manila y en establecer relaciones diplomáticas con España. Entonces no le quedaba a Vizcaíno otro recurso para regresar a la Nueva España que sumarse a dicha empresa de Date Masamune.

Se dedicaron a la construcción del navío y, al terminarlo, lo bautizaron con el nombre de "San Juan Bautista". En la misión iba el general Vizcaíno en condición de simple pasajero, así como fray Luis Sotelo, ${ }^{8}$ quien tomó el mando durante el viaje, junto con otros franciscanos: fray Diego Ibáñez y fray Ignacio de Jesús. Viajaban además el embajador Hasekura Tsunenaga ${ }^{9}$ y 180 japoneses.

La nave zarpó del puerto Tsukinoura en la Península de Oshika, el 28 de octubre de 1613 (el 15 de septiembre del año 18 de la Era de Keicho), y el 25

predicar en su provincia y liberó al misionero prisionero del shogunato fray Luis Sotelo, quien colaboró a construir el barco "San Juan Bautista", en busca de entablar relaciones diplomáticas y comerciales con la Nueva España y la Corona española, Masamune envió una embajada encabezada por Hasekura Tsunenaga, fray Luis Sotelo y 180 personas japonesas.

8. Luis Sotelo (1574-1624), fraile franciscano que nació en Sevilla, España, y estudió en la Universidad de Salamanca. En 1599 se trasladó a la Nueva España. Al llegar a la capital de la Nueva España, los franciscanos se empeñaron mucho para que se quedara y diera clases de teología a los novicios. Así lo hizo por algún tiempo; pero decidido a pasar al Asia pidió y obtuvo el permiso del virrey de la Nueva España, Gaspar de Zúñiga, para embarcarse y se fue a Manila. Gobernaba entonces en las Filipinas el caballero de Santiago, Francisco Tello, con quien Sotelo tenía una vieja amistad, como que eran oriundos de la ciudad hispalense. El padre Sotelo, en cuanto aprendió de sus feligreses algunas palabras en lengua japonesa, preparó su viaje a Japón. Cuando trazaba el proyecto de su viaje, murió su amigo el gobernador Tello. Pedro de Acuña, que le sucedió en el gobierno, no tuvo con él la misma amistad que su antecesor, lo cual le obligó a emprender el viaje, aprovechando la tolerancia que hubo a la muerte de Taico Toyotomi Hideyoshi. (Núñez Ortega, 1923: 36; también, Cruz, Francisco Santiago, op. cit., pp. 43 y 44.) Posteriormente, alrededor de septiembre de 1622, cuando murió Hasekura, se infiltró de nuevo en Japón, entonces lo descubrieron y encarcelaron en Nagasaki. El 25 de agosto de 1624 tras dos años de cárcel de Omura fue sometido a la hoguera (Gonoi, 2003: 244-249).

9. También llamado Hasekura Rokuemon Nagatune (1571-1622), bautizado en Madrid, España, como "Felipe Francisco", fue un "Samurai" que en 1592 se dedicó a participar en la invasión a Corea, bajo el mando del Taico Toyotomi Hideyoshi y posteriormente prestó servicios al Daimyo de Sendai, Date Masamune. Entre los años 1613 y 1620, Hasekura Tsunenaga encabezó una embajada diplomática a la Nueva España y a la Corona española. El día 2 de abril de 1618 zarpó de Acapulco, y el 10 de agosto de mismo año el galeón San Juan Bautista llegó a Filipinas, con Hasekura Tsunenaga y fray Luis Sotelo a bordo. En agosto de 1620 Hasekura llegó a Nagasaki, y luego regresó a Sendai el día 20 de septiembre del mismo año, cuando Masamune declaró la persecución de cristianos en su reino de Sendai. Se cree que falleció alrededor de agosto o septiembre de 1622 (Gonoi, 2003: 265-273). 
de enero llegaron a Acapulco, en donde se efectuó el desembarco en medio de una gran ceremonia. La embajada de Hasekura, Sotelo y 180 japoneses pasaron por Chilpancingo, Iguala y Taxco, visitaron la Catedral de Cuernavaca ${ }^{10}$ y, finalmente, el 24 de marzo llegaron a la ciudad de México, en donde los recibió con altos honores el virrey, Marqués de Guadalcázar.

Posteriormente la misión japonesa compuesta por unos 30 representantes, con Hasekura y Sotelo, partió hacia Veracruz el 8 de mayo de 1614 con el objeto de embarcarse rumbo a España. De ese puerto salió la flota el 10 de junio, haciendo escala en La Habana, y finalmente llegó a San Lúcar de Barrameda, España, el 5 de octubre, luego de una travesía de dos meses y medio.

Este artículo, en conmemoración por los 400 años del aniversario de la Embajada de Hasekura Tsunenaga, se refiere a las razones políticas y el proceso histórico que llevaron al envío de esta misión japonesa.

\section{Relaciones hispano-japonesas en la época virreinal}

De acuerdo con el Tratado de Tordesillas ${ }^{11}$ suscrito por las potencias ibéricas de España y Portugal en el año 1494, se estableció una "línea de demarcación" partiendo la Tierra en dos grandes zonas de navegación: la parte oriental para Portugal, y la occidental para la Corona de España. Este reparto de la Tierra tuvo el poder de impulsar cada vez con más energía los viajes marítimos, tanto para explorar y conquistar nuevos territorios y fomentar el comercio, como para la evangelización de los naturales a la fe cristiana.

A través de una serie de expediciones de Hernán Cortés y fray Francisco José García Jofre de Loaysa se había logrado ampliar el conocimiento de las costas de California. Entonces el lejano Oriente empezó a ser el objeto central de la expansión española en el Pacífico. El viaje de Ruy López de Vi-

10. En la Catedral de Cuernavaca, México, una pintura mural representa la experiencia de los "Veintiséis Mártires de Nagasaki”. En la parte superior del mural dice: "Emperador Taycosama mandó martirizar por..." Entre esos 26 mártires estaba el fraile Felipe de las Casas, también conocido ahora como San Felipe de Jesús, nacido en Puebla, México, y cuya figura actualmente se puede apreciar tanto en la capilla de la Catedral Metropolitana como en la Basílica de Guadalupe, en la ciudad de México.

11. El Tratado de Tordesillas fue firmado el 7 de junio de 1494 por mediación del papa Alejandro VI (Rodrigo Borgia), entre los representantes de Isabel y Fernando, reyes de Castilla y de Aragón, por una parte, y los del rey Juan II de Portugal, por la otra. En este documento se estableció un reparto de las zonas de navegación y conquista del Océano Atlántico y del Nuevo Mundo mediante un meridiano situado 370 leguas al oeste de las islas de Cabo Verde a fin de evitar conflictos de intereses entre las potencias ibéricas de España y Portugal. 
llalobos marcó el principio de este cambio. Zarpó rumbo a las Indias Orientales; desembarcó en las Filipinas; tomó formal posesión, y les dio nombre e intentó regresar a la Nueva España, pero falleció a causa de una enfermedad tropical.

Tras el regreso de los sobrevivientes de la expedición de López de Villalobos, se renovó el interés por las islas Filipinas. El experimentado marino fray Andrés de Urdaneta recibió la orden de Felipe II de acompañar una expedición del general Miguel López de Legazpi, quien llevó a cabo con éxito la conquista de las islas Filipinas en 1565 , pero pronto advirtió la necesidad de establecer una línea de comunicación con América para abastecerse y para transportar las ricas mercaderías del lejano Oriente a España.

Finalmente ambas potencias ibéricas se encontraron en el Asia oriental, donde surgieron los conflictos en torno a quién debería predicar el cristianismo, y también quién tendría los derechos del monopolio comercial; esta problemática alcanzaría también al territorio nipón. Bajo esta circunstancia, comenzaron los contactos e intercambios entre Japón y España a través de sus gobernadores en Manila con la intermediación de las autoridades de la Nueva España

El gran problema era el "tornaviaje" o ruta de regreso del Oriente hasta las costas americanas, lo cual fue indispensable para el tráfico mercantil. El piloto Esteban Rodríguez y el notable marino fray Andrés de Urdaneta, a bordo del navío "San Pablo", abandonaron Manila y llegaron a Acapulco. Desde entonces este derrotero Rodríguez-Urdaneta quedó establecido como la vía regular para el regreso de Manila a Acapulco de los galeones de Manila, o la nao de China. Entonces, Manila se convirtió en el centro del comercio en el extremo Oriente, y así el Imperio español logró establecer la hegemonía en el Océano Pacífico, que duraría por dos siglos y medio.

Finalmente ambas potencias ibéricas se encontraron en el Asia oriental, donde surgieron los conflictos en torno a quién debería predicar el cristianismo, y también quién tendría los derechos del monopolio comercial; esta problemática alcanzaría también al territorio nipón. Bajo esta circunstancia, 
comenzaron los contactos e intercambios entre Japón y España a través de sus gobernadores en Manila con la intermediación de las autoridades de la Nueva España.

Estos contactos con los portugueses y españoles, poco después se desarrollaron bajo el nuevo aspecto de la intervención de otras dos nuevas naciones: Holanda e Inglaterra, que se opusieron por todos los medios a la política de la Corona española de expulsar a los holandeses e ingleses del interior de Japón. Es decir, dichas relaciones tensas y contradictorias se desarrollaron dentro del antagonismo religioso y político que enfrentaban las potencias católicas de España y Portugal y las protestantes de Holanda e Inglaterra, radicadas en Japón.

\section{Relaciones entre Toyotomi Hideyoshi y el gobierno de Manila}

En julio de 1584 dos franciscanos, Juan Pobre y Diego Bernal, y dos frailes agustinos, Francisco Manrique y Pablo Rodríguez, llegaron a Hirado, en el noroeste de la isla de Kyushu, al sur de Japón. El señor de Hirado, Matsuura Takanobu, festejó a los españoles y prometió construir una iglesia, por lo cual entre los españoles en Manila nació la pasión de evangelizar en Japón.

Además, en ese periodo de guerras en Japón, en que se daba gran importancia a los asuntos militares y financieros, llamaba la atención el NanbanBoeki, es decir, el comercio con los países europeos. Especialmente, los señores feudales llamados Daimyo de Kyushu, al sur de Japón, tomaron una actitud muy positiva, convirtiéndose en Kirisitan-Daimyo, es decir, señores feudales cristianos.

Los misioneros portugueses, que estaban enterados perfectamente de esta situación, tomaron medidas para introducir las naos comerciales como medio de ayuda o cooperación para la evangelización. Es decir, la propagación del cristianismo se desarrolló en torno a los puertos comerciales. Así, los jesuitas portugueses habían establecido su propio puesto absoluto en la evangelización en Japón y el comercio con esta tierra. Sin embargo, los franciscanos, agustinos y dominicos apoyados por la Corona española tomarían parte en la obra de evangelizar en Japón, y esto no sería admisible para los jesuitas apoyados por la Corona portuguesa. En consecuencia, surgió una discordia entre España y Portugal en torno al derecho evangélico en Japón, y se intensificó más el antagonismo entre los dos países. 
Ante esta circunstancia, Toyotomi Hideyoshi, ${ }^{12}$ en la misión de pacificar Kyushu, intentó conocer de cerca la situación verdadera de la evangelización cristiana y los dominios de la iglesia en Nagasaki, así como la situación de los señores feudales cristianos Kirisitan Daimyo. Hideyoshi consideró que el cristianismo, y sobre todo los misioneros dirigentes, representaban un peligro por la posibilidad de rebelarse y conquistar el país. Como resultado, promulgó el "Edicto de Expulsión de los Jesuitas", que especificaba los delitos de los sacerdotes de esta orden y obligaba a la expulsión del territorio en 20 días. Sin embargo, este mandato no afectaría al comercio, pues "en cuanto a los barcos extranjeros en tanto que se limiten a actividades comerciales, esta orden no los atañe y el comercio debe siempre llevarse a cabo". ${ }^{13}$ Es decir, Hideyoshi adoptó la política dual de separar claramente la evangelización y el comercio.

En 1596 dos galeones salieron de Manila para Acapulco. Uno, el "San Felipe”, se topó con una tormenta y tuvo que entrar al puerto de Urado en la provincia de Tosa, en la isla de Shikoku. Allí, un magistrado de Hideyoshi, Masuda Nagamori, hizo una investigación y ordenó la confiscación de la carga del galeón debido a la presencia de varios monjes franciscanos entre los españoles. Además, reportaron un testimonio de que: "[los españoles eran] ladrones corsarios, que venían a comerciar la tierra para tomarla, como lo habían hecho en el Perú y en la Nueva España y Filipinas, enviando primero a los padres de San Francisco para que predicaran la ley de ellos", lo cual despertaría la sospecha de atentar contra la unidad nacional propuesta por Hideyoshi.

Finalmente, el 5 de febrero de 1597 fueron crucificados en Nagasaki seis franciscanos, tres jesuitas japoneses y otros 17 cristianos japoneses, a quienes se recuerda históricamente como los "Veintiséis mártires de Nagasaki". ${ }^{14}$ Las

12. Toyotomi Hideyoshi (1537-1598) fue un Daimyo del periodo de Sengoku (Guerras) que realizó la unificación de Japón. Nació en Nagoya, en la provincia de Owari, hogar del clan Oda. Al regresar a Owari se unió al clan Oda como un humilde sirviente. Poco después se convirtió en uno de los portadores de sandalias "waradi" de Oda Nobunaga. Tiempo después se le encargaron tareas más importantes. A pesar de sus orígenes humildes, Hideyoshi se convirtió en uno de los generales más distinguidos de Oda Nobinaga, y tomó el nombre "Hashiba Hideyoshi".

13. Artículo cuarto del Edicto de Expulsión de los misioneros que promulgó Hideyoshi en 1587 (el día 19 de junio de la Era de Tensho) en Hakozaki, Hakata.

14. El 15 de agosto de 1549, los misioneros jesuitas de San Francisco Javier, Cosme de Torres y Juan Fernández llegaron a Kagoshima, al suroeste de Japón, con la esperanza de predicar el catolicismo en Japón. Al principio, el shogunato y la casa imperial apoyaron la misión católica, pensando que reduciría el poder de los monjes budistas y ayudaría al comercio con España y Portugal. Sin embargo, con el tiempo el shogun Hideyoshi consideraba cada vez más al catolicismo como una amenaza y comenzó a perseguir a los cristianos. Posteriormente la religión católica fue prohibida 
noticias de este desastre llegaron a Manila. Entonces, el gobernador Francisco Tello de Guzmán envió como emisario a Luis Navarrete Fajardo, para tratar de reclamar y negociar la indemnización por las pérdidas sufridas por el barco "San Felipe". Sin embargo, Hideyoshi sostuvo su tesis de que bajo las leyes japonesas todos los barcos perdidos en las costas, con sus mercancías, pertenecían al señor de la tierra local. En cuanto a los frailes martirizados no era cosa que pudiera remediarse, y le pedía al gobernador de Manila no enviar más personas como aquéllas, puesto que se habían promulgado nuevas leyes estrictas que prohibían su entrada y fijaban pena de muerte como castigo para los que se consideraran infractores. A partir de ese momento, esos hechos provocaron la suspensión de las relaciones entre el gobernante llamado "Taico" Hideyoshi y el gobierno de Manila.

\section{Relaciones directas entre el shogunato de Tokugawa y el gobierno de la Nueva España}

Relaciones entre el shogun Tokugawa Ieyasu y el gobierno de Manila

La muerte de Hideyoshi llevó al poder a Tokugawa Ieyasu, quien se mostró vivamente interesado en el comercio de Nanban-boeki. Entonces el shogun Ieyasu mandó a fray Jerónimo de Jesús y al gobernador Tello de Guzmán para que se iniciara el tráfico mercantil y que constructores españoles proporcionaran asistencia técnica a Japón, y asimismo ofrecieran que los galeones de Manila utilizaran los puertos japoneses y que se enviaran mineros novohispanos para explorar las minas de oro y plata en Japón.

Ante estas solicitudes, el gobernador Tello de Guzmán desconfiaba de la voluble actitud de Ieyasu hacia los cristianos y no concertó compromisos, hasta que fue sucedido por Pedro de Acuña, quien mandó el buque Santiaguillo, en el que viajaron los franciscanos fray Luis Sotelo y fray Diego de Bermes, para concertar un convenio comercial con Ieyasu.

Una vez conseguido el acuerdo comercial, Ieyasu procuró ampliar sus tratos comerciales con otras naciones europeas. En 1605, la Compañía Ho-

totalmente. Finalmente, el 5 de febrero del año 1597, el gobernante Taico Hideyoshi condenó a muerte a 26 cristianos: seis misioneros franciscanos (incluso un novohispano llamado San Felipe de Jesús), tres jesuitas japoneses y 17 laicos japoneses. Todos ellos fueron ejecutados en la Colina de Nishizaka, en las afueras de Nagasaki. (Nijyuroku Seijin Jyunkyo (Twenty Six Martyrs), Kirisitan Bunka 3 (Cultura Cristiana 3), Nagasaki Bunkensya, Nagasaki, Japón, 2006). 
landesa de las Indias Orientales empezó la ocupación de las Molucas y logró que Japón le abriera las puertas de su comercio.

Entonces el gobernador Pedro de Acuña trató de anular la concesión hecha en favor de la Compañía Holandesa. Con tal propósito envió al capitán Francisco Moreno Donoso y a fray Luis Sotelo para que pidieran a Ieyasu que cancelara el permiso otorgado a los holandeses, alegando que los holandeses podrían atacar los navíos españoles que llegaran a los puertos de Japón. Sin embargo, tales gestiones se suspendieron con la muerte del gobernador Pedro de Acuña.

Ante la ausencia del mandatario en Filipinas, el rey de España mandó al virrey Velasco nombrar un gobernador interino en tanto llegaba el gobernador definitivo Juan de Silva. Entonces el virrey Velasco se dirigió a su sobrino Rodrigo de Vivero y Velasco, gobernador de Nueva Vizcaya, quien partió de Acapulco el 15 de marzo y llegó sin novedad a Manila el 13 de junio de 1609. Sin embargo, la preocupación primordial de Vivero fue, de momento, asegurar las defensas contra posibles ataques de los holandeses.

Cuando arribó el gobernador definitivo Juan de Silva, Vivero partió con destino a Acapulco a bordo del "San Francisco", acompañado del "Santa Ana" y el "Santiago". Los barcos se encontraron con mal tiempo; el "Santa Ana" logró escapar a un puerto de Bungo, en Kyushu, mientras el "San Francisco" naufragó el 30 de septiembre de 1609 en la costa del pueblo de Iwawada, Onjuku, en la Península de Boso, al sur de Edo (actual Tokio).

Negociaciones de Rodrigo de Vivero con el shogun Ieyasu

Vivero y otros 317 náufragos novohispanos fueron bien recibidos por el señor local de Otaki, Honda Tadatomo. Unos días después lo invitaron a pasar a su corte, donde recibieron a Vivero con una gran cortesía. Después de una entrevista con Tokugawa Ieyasu y su hijo Hidetada, Vivero visitó a un alto funcionario del shogunato y manifestó las tres siguientes solicitudes: que se diera buen trato a los misioneros españoles, que se mantuvieran las relaciones amistosas y comerciales entre España y Japón, y que se expulsara a los holandeses de los puertos de Japón. Unos días después informaron a Vivero que Ieyasu estaba dispuesto a permitir obrar libremente a los misioneros y que deseaba la amistad con España; pero que no podía suspender el comercio con los holandeses, puesto que se les había concedido licencia por un año. Además agregó que Ieyasu había decidido proporcionar a Vivero una embar- 
cación para poder viajar a la Nueva España; y le solicitó que se hiciera cargo de conseguir 150 mineros novohispanos para trabajar en las minas de Japón. Respondió Vivero que no podía acceder a este pedimento sin consultar con el rey, asegurando que se embarcaría en el "Santa Ana", reparado en Bungo.

Como resultado de estas conversaciones, Vivero formuló un acuerdo preliminar en las llamadas "Capitulaciones", ${ }^{15}$ cuyo esbozo hecho el 20 de diciembre de 1609 presentaron a Ieyasu a través de fray Luis Sotelo, con quien se encontró en la iglesia de Fushimi en Kyoto y le encargó todo para negociar con Ieyasu. En cuanto al inicio del comercio, propuso: 1. Que se permitiera el establecimiento de una factoría para el comercio español en Kanto (la región actual de Tokio, Kanagawa, Saitama y Chiba), similar a la de Nagasaki, con almacenes, astilleros e iglesias. 2. En caso de naufragio, en cualquier parte de Japón, no se haría ningún daño a las naves novohispanas y filipinas. 3. Se les venderían los aprovisionamientos a precios comunes en Japón. 4. Se recibiría a un embajador español con todos los honores y se le dotaría de una residencia oficial y una iglesia, dándosele al mismo tiempo derecho de adquirir subsistencias a precios regulares y de importar bienes libres de gravámenes.

Vivero estuvo de acuerdo en procurar conseguir 100 ó 200 mineros novohispanos pero con base en las siguientes condiciones: 5 . Deberían ser enviados mineros españoles a las minas de Japón con sus más modernos procesos. El rey Felipe III debería decidir el envío de 100 ó 200 mineros. Los mineros mismos recibirían en pago la mitad de toda la plata que se extrajera de las minas, en tanto que la otra mitad se dividiría equitativamente entre el shogun japonés y el rey de España. Si un español encontraba nuevas vetas en las minas, debería recibir un porcentaje de la plata que rindieran. El azogue (mercurio) habría de proveerse a precios regulares. Se permitiría a los mineros novohispanos tener iglesias y sacerdotes. 6 . Se proveerían facilidades espirituales para los mineros cristianos y se establecerían representantes del shogun y del rey español en los centros mineros. Tanto los españoles como los japoneses tendrían sus propios órganos judiciales para castigar crímenes cometidos en favor de sus paisanos. Es decir, los mineros novohispanos quedarían bajo la jurisdicción de su embajador o de un capitán de navío y los japoneses bajo la de sus propias autoridades. 7. Puesto que era un gran honor estar aliado con el más grande rey del mundo, los holandeses deberían ser expulsados de inmediato, puesto

15. Consúltese anexo 1. Para más detalles sobre las "Capitulaciones" hechas por Vivero para Ieyasu, véanse: Knauth, 1972: 194-195; Mathes 1973: 91-94; véanse también: Ariza Corres, 1926: 60-63. 
que siendo el más bajo país del mundo, no traían ninguna ganancia a Japón y estaban dañando la navegación española. Sería imposible tener relaciones amistosas si esta provisión no se llevaba a cabo. 8. Todos los puertos serían sondeados, de manera que las naves españolas que sufrieran tormentas, pudieran ser remolcadas sin peligro. Por último, Vivero señaló que el acuerdo sería provisional y que estaría sujeto a la aprobación del rey de España, quien respondería dentro de los dos años siguientes.

Dichas "Capitulaciones" serían basadas en una idea muy particular del mismo Vivero, quien tendría un plan especial al respecto. Vivero entendió bien de la "grandeza y riqueza del Japón", ${ }^{16}$ e insistía en que "convendría que Vra. Majestad conservara la amistad del emperador del Japón [Ieyasu] y siendo necesario para ello enviar una nao de la Nueva España"; ${ }^{17}$ además consideró que el país de Japón estaba "dividido en sesenta y seis reinos" ${ }^{18}$ y estaba unificado por "uno de los ricos monarcas del mundo"19 que gozaba de gran riqueza de oro y plata. Y apreciaba su alta producción de plata en las abundantes minas, sin conocer los procesos para extraer la plata de que "los veneros y minas de plata son de suerte que con faltarles a los japoneses industria y traza para sacarla tienen tanta en cantidad que admira. También sacan oro de ríos y de minas". ${ }^{20} \mathrm{Y}$ prestó atención al poder adquisitivo y recursos financieros del pueblo japonés. Además, percibió la importancia y utilidad del comercio con Japón, por lo tanto intentó aumentar los ingresos de la Corona española, y con su experiencia como alcalde mayor del pueblo y minas de Taxco, México, y sus conocimientos sobre la industria minera, planeó el porcentaje para recibir

16. Carta que Rodrigo de Vivero escribe a Su Majestad desde el Japón, Usnki (Usuki), Reino de Bungo, Mayo de 1610", en Ariza Corres, 1926: 99.

17. Carta que Rodrigo de Vivero escribe a Su Majestad desde el Japón, Usnki (Usuki), Reino de Bungo, Mayo de 1610", en Ariza Corres, 1926: 98.

18. Carta que Rodrigo de Vivero escribe a Su Majestad desde el Japón, Usnki (Usuki), Reino de Bungo, Mayo de 1610", en Ariza Corres, 1926: 99.

19. Carta que Rodrigo de Vivero escribe a Su Majestad desde el Japón, Usnki (Usuki), Reino de Bungo, Mayo de 1610", en Ariza Corres, 1926: 99.

20. A partir del periodo medio del siglo XVI empezó la explotación minera, y sobre todo entre la Era de Keicho y la de Genna se explotaron en gran escala las minas de oro y plata en Japón, como las de Iwami-Omori, Tajima-Ikuno y Sado-Aikawa. Desde el año 1581 hasta 1600 el promedio anual de la producción mundial de plata fue de unos 420 mil kilogramos (74,300 kilos de la Nueva España, 46,000 kilos del Perú y 254,300 kilos de Potosí). En cambio, el promedio anual de la cantidad de exportación de plata japonesa fue entre 170 mil y 180 mil kilos, que significa que la producción de plata en Japón fue bastante alta a escala mundial. Es decir que la plata producida en Japón sostenía el comercio exterior de Japón. (Véanse, Ohada, 1976a: 6; Ohada, 1976b: 7 y 8, 235 y 236. Véanse también, Iwao, 1976: 222 y 223). 
en pago por la plata descubierta, entre el shogun japonés y el rey de España. Vivero deseaba que el rey de España reinara en el país de Japón que "sea útil a Vra. Majestad entrar en monarquía tan grande, tan próspera y extendida, no es menester mucho para probarlo y así pareciéndome que sólo le faltaba a esta tierra el tener a Vra. Majestad por su rey". ${ }^{21}$ Vivero se había desvelado en pensar "por qué caminos se había esto hacer posible y hallando cerrados los de las armas porque por fuerza de ellas, la multitud de la gente y la fortaleza de los sitios era imposible emprenderlo". 22 Sin embargo, propuso las razones para comenzar una guerra contra Japón con el pretexto de que "[...] bien justificada tenía Vra. Majestad la guerra y segura su real conciencia, con el martirio de los religiosos de San Francisco y agravios hechos a la nao San Felipe y últimamente con el suceso de la de Macao". ${ }^{23}$

Vivero suponía que "por verdad cierta como lo es la dificultosa entrada por fuerza de armas no queda medio que elegir sino aficionar las voluntades al servicio de Vra. Majestad por el camino que Dios nos va abriendo, por la predicación del esto". ${ }^{24}$ Además Vivero sabía que "pasen de trescientos mil cristianos los que tiene el Japón", ${ }^{25}$ y pensaba que "ampliándose y creciendo el número de los cristianos con muy esforzadas esperanzas se podría pensar que muerto este Emperador [Ieyasu], y otro [Hidetada]", ${ }^{26}$ trazó una medida concreta para tomarla de que "[...] es el asunto verdadero meter religiosos y religiones en estas partes dividiéndolos diversamente a título de que se pueblan con los españoles en las minas o sus cercanías para que vayan obrando y sacando el fruto que he referido [...]" ${ }^{27}$ Es decir, tenía planeado tomar y poseer el territorio de Japón, por medios como el aumento de los cristianos japoneses a través de la evangelización en las provincias de Japón, y la rebelión con los fieles japoneses a la muerte de Ieyasu. Por lo tanto, para aumentar el número de cristianos japoneses, ponía énfasis en dichas "Capitulaciones" en las que debería permitirse a los mineros novohispanos tener iglesias y sacerdotes, y planeaba que se construyeran iglesias en las minas del territorio de Japón. Dichas "Capitulaciones" estaban basadas, de alguna forma, en una idea muy

21. Carta que Rodrigo de Vivero escribe a Su Majestad..." en Ariza Corres, 1926: 100.

22. Carta que Rodrigo de Vivero escribe a Su Majestad..." en Ariza Corres, 1926: 100.

23. Carta que Rodrigo de Vivero escribe a Su Majestad..." en Ariza Corres, 1926: 100.

24. Carta que Rodrigo de Vivero escribe a Su Majestad..." en Ariza Corres, 1926: 100.

25. Carta que Rodrigo de Vivero escribe a Su Majestad..." en Ariza Corres, 1926: 101.

26. Carta que Rodrigo de Vivero escribe a Su Majestad..." en Ariza Corres, 1926: 101.

27. Carta que Rodrigo de Vivero escribe a Su Majestad..." en Ariza Corres, 1926: 101. 
particular de Vivero para que se estableciera una sede para la predicación cristiana y el comercio en la región Kanto del gobierno del shogunato, al entrar en Japón, de la misma forma que la Corona portuguesa lo había hecho con la construcción de instalaciones en la ciudad portuaria de Nagasaki al sur de Japón. Vivero insistía en que para mantener las relaciones amistosas y garantizar la seguridad de las naves novohispanas, debería expulsarse a los holandeses, enemigos de España, además de permitirse la demarcación y sondeo de todas las costas del Japón.

De acuerdo con Vivero - como hemos visto y según una carta que escribió éste al rey de España - era necesario mantener buenas relaciones con Japón, pese a la actitud opuesta de algunas órdenes religiosas, ya que España podía obtener de Japón algunos beneficios. Se trataba de una nación formada por 66 reinos gobernados por un emperador que recibía grandes riquezas en oro y plata por concepto de tributos. El país oriental, cuyas tierras eran fértiles y de buen temperamento, contaba con una población numerosa y muchas ciudades limpias y bien organizadas; estaba fortificado y sus ejércitos armados con arcabuces, espadas, lanzas y picas, de modo que la conquista de Japón sería en todo caso extremadamente difícil, aunque estaría justificada por los martirios en Nagasaki, así como por los incidentes del galeón "San Felipe" y el "Madre de Deus". Sin embargo, en Japón había 300 mil cristianos, de suerte que, si lograba incrementarse el número de cristianos con la labor de los misioneros, este sector podría rebelarse a la muerte de Ieyasu y proclamar al país como posesión española. El único modo de alcanzar tal objetivo era mediante la formulación de un acuerdo con el shogun Ieyasu, que permitiera la entrada de sacerdotes y mineros novohispanos, quienes habrían de ayudar a la conversión de los japoneses. El convenio debía prevenir el envío anual de un barco mercante de Manila y la autorización para que arribaran a Manila los juncos japoneses; se habrían de proporcionar asimismo operarios (obreros) para fomentar la minería en Japón. Con esto, la Corona española podría obtener oro y plata de la explotación de las minas y del comercio con telas de algodón de la Nueva España; conseguiría también un puerto de escala en las costas japonesas para la nao de Manila. Finalmente Vivero suplicó la anuencia real para las negociaciones con Japón, lo que favorecería la penetración hispánica y ayudaría a lograr la expulsión de los holandeses.

Conforme a las "Capitulaciones" propuestas por fray Luis Sotelo, el gobierno del shogunato de Tokugawa concluyó las "Capitulaciones y asientos de 
$\mathrm{Paz}{ }^{28}$ de este modo: 1 . El shogun Ieyasu otorgaba salvoconducto a los barcos novohispanos para que fondearan en cualquier puerto japonés, y concedía a España terrenos para la construcción de almacenes y casas. 2. Garantizaba libertad de entrada y movimiento a todos los sacerdotes que se trasladaran a Japón. 3. Daba a los barcos de Manila autorización para invernar o abastecerse en los puertos japoneses. 4. Proveía materiales para la reparación de navíos españoles a precios regulares. 5. Se comprometía a recibir a un embajador con los máximos honores. Y solicitaba en cambio que los barcos japoneses pudieran llegar a la Nueva España y que se instituyera un consejo formado por mercaderes de ambos países para que fijara los precios de los productos con que se iba a comerciar. Por último, mencionaba que "estas susodichas capitulaciones ofrece y consiente el Sr. de Japón y da su palabra de guardarlas y cumplirlas perpetuamente sin quebrantar ninguna", ${ }^{29} \mathrm{y}$ le nombraron a fray Luis Sotelo como portador del mensaje y embajador del shogun.

Sin embargo, por medio de petición de Vivero, finalmente fue designado fray Alonso Muñoz como representante de Ieyasu, y para acompañarlo fueron escogidos 23 comerciantes japoneses. Ieyasu dio a Vivero cuatro mil ducados y proporcionó para el viaje el barco "San Buenaventura", construido por el piloto inglés William Adams. Dicha embajada salió el 1 de agosto de 1610 de Uraga y llegó el 27 de octubre a Matanchén, en las costas de Nayarit, y unos días después a Acapulco.

A su arribo a Matanchén, Vivero escribió al rey abundando en las razones que había para establecer relaciones cordiales con Japón y apremiando el envío de una embajada a Ieyasu; quienes formaran parte de la embajada podrían explorar las costas japonesas y partir en busca de las islas Rica de Oro y Rica de Plata. Con la llegada de Vivero a la Nueva España y en virtud de sus reiteradas proposiciones para la expansión en el lejano Oriente, se introdujo un elemento nuevo en el programa español del Pacífico. Suspendida por el momento la expedición a las islas Rica de Oro y Rica de Plata, se empezaron a tomar providencias para que se hiciera una visita a Japón.

28. Consúltese anexo 2. Los detalles de las "Capitulaciones y asientos de Paz", traducidas por fray Luis Sotelo, véanse, Ariza Corres, 1926: 69-71.

29. "El universal señor de Japón. Minamotono y eas (Ieyasu) suplica al Duque de Lerma en España manifiesta esta carta a la suprema magestad. Habiendo tratado en Gobernador pasado de Luzón de que venga navío de Nueva España al Japón, pareció bien, y así en cualquiera parte de todo él donde llegare el navío será bien recibido, no se le hará agravio alguno, sino todo favor y regalo. Todas las demás cosas menudas tratará este padre embajador Fray Luis Sotelo”. En Ariza Corres, 1926: 69. 


\section{Relaciones entre el embajador Sebastián Vizcaíno y el shogunato de Tokugawa}

Entonces el virrey de la Nueva España, Luis de Velasco II decidió mandar una embajada a Japón. Según el plan, el general Sebastián Vizcaíno, quien representaba el expansionismo novohispano en el Pacífico, iría como jefe de la expedición y tendría el carácter de embajador ante Tokugawa Ieyasu y su hijo Hidetada; ante ellos, solicitaría permiso para demarcar y sondear las costas japonesas, y luego regresaría a la Nueva España, pasando por las islas Rica de Oro y Rica de Plata. Sin embargo, no fue posible establecer el comercio directo entre Japón y la Nueva España, como había requerido Ieyasu, debido a que no se había consentido la evangelización y se habían capturado algunos galeones. Además, tampoco se consideró la importancia del comercio directo con Japón, aún en circunstancias inciertas, que pudiera afectar las relaciones comerciales entre Manila, Filipinas y la Nueva España. Al final, el embajador Vizcaíno no llevó una respuesta clara ante el shogunato de Tokugawa, en lo que se refería al comercio directo con la Nueva España (Bernal, 1965: 67 y 68).

La expedición de Vizcaíno salió de Acapulco el 22 de marzo de 1612 a bordo del navío "San Francisco", llevando consigo a un representante del shogunato, Tanaka Shosuke, quien se había bautizado en México con el nombre de Francisco de Velasco, y otros 22 japoneses que trajo Vivero, acompañado del comisario de San Francisco, fray Pedro Bautista; del lector de teología fray Diego Ibáñez, de fray Ignacio de Jesús, y tres legos más. Llevaba el navío por piloto a Benito Palacios, con 51 marineros, y trazaron una ruta directa a Japón, a donde llegarían el 10 de junio de 1611 al puerto de Uraga, cerca de Edo (actual Tokio).

A su arribo, Vizcaíno escribió a Ieyasu informándole sobre el propósito de su viaje como portador de una embajada del virrey de la Nueva España para agradecer los regalos enviados al virrey y pagar la suma que se había ofrecido a Vivero, así como el importe del navío San Francisco. Escribió también a su hijo Hidetada y quedó en espera de las respuestas de ambas partes. Días después, el 22 de junio, el embajador Vizcaíno, "acompañado por dos cortesanos y 4 mil guardias japoneses, así como por fray Luis Sotelo como intérprete, fray Pedro Bautista, fray Diego Ibáñez, el sargento Juan de la Hoz, Lorenzo Vázquez, que llevaba un arcabuz; el escribano Gascón de Cardona, que portaba 
el estandarte real, y el piloto Benito de Palacio, que conducía los regalos", 30 fueron recibidos por Hidetada en el palacio. Después de visitar a varios altos funcionarios y secretarios del shogunato, el día 25 de junio, al dirigirse a la iglesia de San Francisco en la ciudad de Edo, se encontró por casualidad con el Daimyo de Sendai, Date Masamune, quien pidió al embajador Vizcaíno que disparara sus arcabuces; entonces se hicieron dos descargas, cuyo estruendo hizo que algunos samurais cayeran de sus caballos; el Daimyo Masamune rió de buena gana y le agradeció al embajador.

Cuando visitó el 6 de julio al secretario del shogun, Honda Kozukenosuke Masazumi, pidió ante Ieyasu "permiso para construir una embarcación pequeña y para formar un mapa de las costas japonesas que sirviera a los barcos de Manila; solicitó asimismo se le permitiera adquirir aprovisionamientos a precios regulares y vender sus mercancías" en el puerto de Uraga (Mathes, 1973: 103; Núñez Ortega, 1923: 70; Santiago, 1964: 28). Unos días después Vizcaíno recibió la respuesta aprobatoria y la invitación de Ieyasu, con lo que aprovechó la oportunidad para pedir la expulsión de los holandeses de Japón, insistiendo en que "los holandeses se habían rebelado contra España y que sus posibles ataques ponían en peligro la seguridad de la ruta ManilaJapón" (Mathes, 1973: 103; Núñez Ortega, 1923: 70; Santiago Cruz, 1964: 28). La respuesta de parte del shogunato para esto fue que "su país había concertado convenios que no era fácil desconocer, pero que se tomaría una decisión definitiva antes de que la embajada regresara a la Nueva España" (Mathes, 1973: 103).

Una vez terminada la preparación, Vizcaíno zarpó del puerto de Uraga con el propósito de dar principio a la demarcación de las costas japonesas. Navegó sobre la costa oriental del Pacífico; así, el primero de noviembre de 1611 ancló en el puerto de Shiogama, del principado de Sendai que gobernaba el Daimyo Date Masamune. El día 8 del mismo mes entró en la ciudad de Sendai, y el día 10 visitó el castillo de Aoba en donde vivía Masamune, quien "lo recibió cordialmente y, dado que simpatizaba con la religión cristiana, se mostró interesado en facilitar un puerto para las naos de Manila y en establecer relaciones diplomáticas con España" (Mathes, 1973: 104). Con la ayuda de Masamune,

30. Relación del viaje hecho para el descubrimiento de las islas llamadas <Ricas de Oro y Plata>, situadas en el Japón, siendo Virrey de la Nueva España D. Luis de Velasco, y su hijo, Sebastián Vizcaíno, general de la Espedición, Documentos inéditos del Archivo de Indias, Sevilla, España, p. 125.; "Datos históricos..., Embajada del General Sebastián Vizcaíno”, op. cit., p. 18 y pp. 87 y 88; también, Núñez Ortega, 1923: 60. 
Vizcaíno se dedicó a la exploración hasta el 2 de diciembre, cuando sufrieron los efectos de un temblor de tierra y un maremoto, por lo que el día 5 regresó al puerto de Shiogama. Entonces Vizcaíno se enteró de que Masamune mismo "tenía planes para construir un barco y mandar una embajada al virreinato novohispano y a la propia España, con el propósito de conseguir religiosos que trabajaran en las misiones de Japón" (Mathes, 1973: 105).

Pero durante la ausencia de Vizcaíno, los holandeses e ingleses habían esparcido el rumor de que la demarcación emprendida en las costas japonesas, así como la exploración hacia las islas Rica de Oro y Rica de Plata, no tenían otro objeto que preparar la invasión de Japón; que los españoles intentarían igual lo que habían hecho en la conquista de México y Perú. Como consecuencia de estas versiones, se despertó en las autoridades del shogunato una gran desconfianza ante los españoles. Cuando Vizcaíno fue a despedirse de Ieyasu y se enteró de que éste había mudado su actitud hacia los españoles, se le informó que había órdenes para que se destruyeran las iglesias cristianas. Enterado del súbito cambio de la política japonesa, Vizcaíno zarpó de Uraga el 16 de septiembre de 1612 para emprender la búsqueda de las islas Rica de Oro y Rica de Plata. Sin embargo, la búsqueda de dichas islas fue infructuosa, ya que su cansada tripulación dudaba abiertamente de la existencia de dichas islas. El día 14 empezó un viento intenso se tornó en un violento tifón y el navío San Francisco empezó a hacer agua, por lo que decidió regresar inmediatamente a Japón.

El 7 de noviembre Vizcaíno llegó a Uraga con su barco completamente deteriorado. No pudo conseguir audiencia con Ieyasu y, en el mes de abril de 1613 , le hicieron saber que no se le podría proporcionar ayuda alguna debido a que "se le consideraba un deudor inseguro" (Mathes, 1973: 106 y 107). Por todo esto Vizcaíno decidió vender sus propios efectos a fin de poder conseguir fondos para reparar el San Francisco, medio en el que volvería a la Nueva España. Sin embargo nada pudo hacerse. Para entonces Vizcaíno se encontraba agobiado por las preocupaciones y la desesperación, y cayó enfermo. Pese a todo, tuvo la suerte de recibir la oferta de un contrato para colaborar en la construcción del navío de Date Masamune, con quien fray Luis Sotelo "había formulado planes para que una representación del principado de Sendai fuera a entrevistarse con el rey de España y con el Papa" (Mathes, 1973: 107). Pues dicho religioso, "con el deseo de proseguir la obra de cristianización pese a la oposición de los gobernantes de Japón, había procurado ganarse la amistad de Date Masamune" (Mathes, 1973: 107), y por eso Sotelo "se había propuesto 
forzar a Vizcaíno a cooperar con sus planes para darle cierto carácter oficial a la embajada" (Mathes, 1973: 107). No quedaría a Vizcaíno otro recurso para regresar a la Nueva España que sumarse a la empresa de Date Masamune. Se comprometió a colaborar en la construcción del barco que él capitanearía, llevando como embajador a Hasekura Tsunenaga, el capitán de la guardia del príncipe, acompañado con fray Luis Sotelo y otros japoneses a la Nueva España.

\section{Conclusión}

Al terminar la construcción del navío, éste fue bautizado con el nombre de "San Juan Bautista". Por su parte, Date Masamune preparó las "Capitulaciones y asientos de Pases" al virrey de la Nueva España con fecha 16 de octubre de 1613, diciéndole que "para que la santa ley de Dios sea predicada en mi reino y para que mis vasallos se hagan cristianos, pido se me haga merced de enviarme Padres de la Orden de San Francisco, en lo cual no pondré impedimiento alguno, antes favoreceré de veras para que tenga efecto y en todo acomodaré y regalaré a dichos Padres". ${ }^{31}$ En esta carta Masamune pedía además que

[...] se me haga merced de darme pilotos y gente de mar para la navegación de la dicha nao; si las naos de Luzón que van a la Nueva España llegaren a mi reino serán bien recibidas; si Vuestra Excelencia quisiere mandar fabricar naos en mi tierra daré para ello madera, carpinteros, herreros y todas las demás cosas necesarias a los precios comunes; si viniere alguna nao será bien recibida; si en algún tiempo algunos españoles se quisiesen quedar en mis tierras a vivir, les daré sitio y tierras; a los ingleses y holandeses y a cualquier otros que fueren enemigos del Rey de España y si vinieren a mi reino haré justicia de todos ellos y los mandaré matar (Santiago Cruz, 1964: 48 y 49).

Finalmente expresaba que "estas pases y asientos entre el Señor Virrey de la Nueva España y el Rey de Voxu [Oshu], Date Masamune, perpetuamente se han de guardar y cumplir de entrambas partes sin faltar en cosa alguna" (Santiago Cruz, 1964: 48 y 49).

Dicha embajada incluía 180 personas en total, entre quienes se encontraban Hasekura Tsunenaga, Imaizumi Sakan, Matsuki Chusaku, Nishi Kyusuke,

31. Capitulaciones y asientos de pases entre el rey de Voxa, y Date Masamune, y el señor virrey de Nueva España. En Santiago Cruz, 1964: 48 y 49. 
Tanaka Taroemon, Naito Janjyuro, y otros japoneses, junto con la gente de Vizcaíno. A bordo del "San Juan Bautista" esta misión partió de Tsukinoura, cerca de Sendai, el 27 de octubre de 1613 y llegó a Acapulco el 25 de enero de 1614.

Las relaciones entre Japón, Nueva España y España germinaron a partir del antagonismo y el deseo de conseguir el monopolio del comercio y la evangelización en el territorio nipón, protagonizado por las poderosas naciones ibéricas, España y Portugal. Posteriormente, dichas relaciones se desarrollaron en la estructura también antagonista de intervenir para la expulsión de los holandeses e ingleses, es decir, en la confrontación entre los poderosos católicos de España y Portugal, y los protestantes de Inglaterra y Holanda.

Las relaciones amistosas y comerciales entre el shogunato y el virreinato no llegaron a ninguna conclusión, debido a que tanto la Corona española como el gobierno novohispano insistían en la evangelización de Japón para el inicio del comercio, exigencias que el shogunato rechazaba totalmente.

Por otra parte, Holanda e Inglaterra se aproximaron al shogunato sin tocar el tema religioso, en una maniobra política dirigida contra los españoles, llegando a establecer ambas potencias un acuerdo de intercambio comercial.

Posteriormente, en 1623 llegaría una embajada de Manila a Japón, pero no pudo conseguir audiencia con el shogunato, recibiendo la información de que no estaba permitida la predicación del cristianismo en Japón y se romperían absolutamente las relaciones con Manila, por lo cual el comercio con Filipinas, así como las relaciones con la Nueva España y la Corona española fueron interrumpidas.

\section{Referencias bibliográficas}

Ariza Corres, Cristóbal (1926), “Capitulaciones con el Emperador del Japón”, Datos históricos sobre Don Rodrigo de Vivero y el general Sebastián Vizcaíno encontrados en el Archivo de Indias, España.

Ballesteros Gaibrois, Manuel (1947), "Don Rodrigo de Vivero: Su vida y su obra", Documentos inéditos para la historia de España, tomo V, Madrid, España.

Bernal, Rafael (1965), México en Filipinas: Estudio de una transculturación, México: Universidad Nacional Autónoma de México-Instituto de Investigaciones Históricas, pp. 67 y 68. 
De Jarmy Chapa, Martha (1983), La expansión española hacia América y el Océano Pacífico: II. La Mar del Sur y el impulso hacia el Oriente, México: Universidad Nacional Autónoma de México.

De la Torre Villar, Ernesto (comp.), (1980), La expansión hispanoamericana en Asia, siglos XVI y XVII, México: Fondo de Cultura Económica.

De Vivero, Rodrigo (1934 [1609]), Relación del Japón, Introducción y notas de D. Manuel Romero de Terreros, México: Publicaciones del Museo Nacional de México/Secretaría de Educación Pública.

Gil, Juan (1991), Hidalgos y samurais: España y Japón en los siglos XVI y XVII, Madrid: Alianza Editorial.

Gonoi, Takashi (2003), Hasekura Tsunenaga, Yoshikawa-Kobunkan, Tokio, Japón, pp. 244-249.

Iwao Seiichi (supervisor), (1976), Kaigai-koshosi no siten (Un punto de vista para la historia de relaciones extranjeras de Japón), Tokio, Japón: NihonShoseki, pp. 222 y 223.

Knauth, Lothar (1972), Confrontación transpacífica. El Japón y el nuevo mundo hispánico, 1542-1639, México: Universidad Nacional Autónoma de MéxicoInstituto de Investigaciones Históricas, pp. 194 y 195.

Mathes, Michael W. (1973), Sebastián Vizcaíno y la expansión española en el Océano Pacífico: 1580-1630, México: Universidad Nacional Autónoma de México-Instituto de Investigaciones Históricas.

Matsuda, Kiichi (1969), Embajada del Keicho (Embajada de Hasekura Tsunenaga), Shin-Jinbutsu Ourai-sya, Tokio, Japón.

Molina Memije, Antonio M. (1992), América en Filipinas, España: MAPfre.

Murakami, Naojiro (1941), "Sebastian Vizcaíno no Keireki (Historia personal de Sebastián Vizcaíno)”, Vizcaino Kin-gin-to Tanken Hokoku, (Relación de expedición de las Islas Rica de Oro y de Plata de Vizcaíno), Tokio, Japón, pp. III-IV.

Núñez Ortega, Ángel (1923), "Noticia histórica de las relaciones políticas y comerciales entre México y el Japón, durante el siglo XVII", Archivo Histórico Diplomático Mexicano, núm. 2, México: Secretaría de Relaciones Exteriores. Ohada, Jyun (1976a), 16-17 Seiki niokeru Kyokuto no Gin no ryutsu (Distribución de la plata en el Extremo Oriente en los siglos XVI y XVII), Japón: Editorial de la Universidad de Hosei, p. 6.

- - (1976b), Kin-gin bouekisi no kenkyu (Estudio sobre la historia del comercio de oro y plata), Japón: Editorial de la Universidad de Hosei, pp. $7,8,235-236$. 
Santiago Cruz, Francisco (1962), La Nao de China, México: Jus. (1964), Relaciones diplomáticas entre la Nueva España y el Japón, México: Jus.

Serrano Mangas, Fernando (1992), Función y evolución del galeón en la carrera de Indias, España: MAPFRE.

Yaginuma, Koichiro (1988), "Relaciones entre Japón y la Nueva España en el siglo 17", Boletín de Estudios Latinoamericanos, Japón: Sociedad de Estudios Latinoamericanos de Japón, núm. 8, pp. 83-122.

- (1992), "Contactos entre Japón y España a través de la Nueva España en el Pacífico”, Laberinto de las Indias 1492-1992, Tokio, Japón: Keiso-Shobo. (1993), "Capitulaciones de Rodrigo de Vivero ante el Shogunato -Puntos de vista para un estudio sobre las relaciones entre Japón y España a través de la Nueva España-“, The Journal of Kanda University of International Studies, núm. 5, pp. 43-71.

- (1994a), “Japón y México 1 -Inicio de contactos entre Japón y México-”, Radio Supeingo Koza (Curso de Español por radio), Nihon Hoso Kyokai (NHK), Tokio, enero.

(1994b), “Japón y México 2 -Shogunato y Virreinato de Nueva España-", Radio Supeingo Koza (Curso de Español por radio), Nihon Hoso Kyokai (NHK), Tokio, febrero.

(1994c), “Japón y México 3 — Tratado de Amistad, Comercio y Navegación entre Japón y México-", Radio Supeingo Koza (Curso de Español por radio), Nihon Hoso Kyokai (NHK), Tokio, marzo.

_- (1994d), "Tratado de Amistad, Comercio y Navegación entre Japón y México: Una perspectiva para el estudio de las relaciones entre Japón y México en la época moderna", The Journal of Kanda University of International Studies, núm. 6, pp. 259-274.

- - (2003), “Japón y los países hispanohablantes", Radio Supeingo Koza (Curso de Español por radio), Nihon Hoso Kyokai (NHK), Tokyo, abril de 2003-marzo de 2004.

- - (2010), "Japón y México: Trayectoria de 400 años de contactos", The Kanda Journal of Global and Area Studies, núm. 1, pp. 9-52.

- - (2012), "Hegemonía del Imperio español en el Océano Pacífico: Su política expansionista y avance al Sudeste asiático de la Corona española", The Journal of Kanda University of International Studies, núm. 24, pp. 203-223. (2013), "Relaciones en la Cuenca del Pacífico del Imperio español: Política colonial y administrativa de España en las Filipinas", The Journal of Kanda University of Intenational Studies, núm. 25, pp. 283-306. 
(2014), "Relaciones entre el Oriente y el Occidente: Iberoamérica, Asia y Japón en la época de grandes navegaciones", The Journal of Kanda University of International Studies, núm. 26, pp. 89-115.

Yaginuma, Koichiro, et al. (traducción), (1988), El Galeón de Acapulco, Japón: Embajada de México en Tokio.

\section{Anexo 1. Sobre las "Capitulaciones" hechas por Vivero para Ieyasu}

"Las cláusulas y condiciones que D. Rodrigo de Bivero propone a su Alteza el Emperador del Japón. Para tratar con el Rey D. Phelipe su Sr y suplicarrle embíe Vna nao a estos Reynos y seentable el comercio en ellos de los españoles son los siguientes:

- Primeramente a los españoles a de dar su Alteza el puerto de quantó Para que en él desembarquen y tengan almacenes y astilleros con permiso que se pueble de los que fueren menester Para el socorro de las naos y harmadas y en él como Xpianos tengan yglesias y religiosos como en Nangazaque.

- Que a este puerto puedan benir las naos de Na. España y las de las yslas Philipinas cada año y a todos los demás Puertos del Japón sin que Reciban agravios en sus personas y haciendas sino que an de ser bien recevidos y tratados En cualquier Manera que bengan assí de arribada como perdidos o de principal yntento de benir a la dcha tierra.

- Que a estas naos se les a de dar bastimentos a precios justos y moderados y oficiales para la fábrica dellas todo copiosamente y a los precios comunes que corrieren en el Japón.

- Que suponiendo que haciendo comercio y trato de las yslas Philipinas y de la nueba España ciempre abrá negocios que tratar con su alteza y que si el Rey D. Phelipe su señor quisiere para ellos ynbiar enbajador y te nello en su corte a de ser recevido honrrado y aposentado como se debe a ministro de Tan gran Monarca y rey y él y sus criados y los sacerdotes que trajere an de tener seguro y cassa donde se ospeden y Iglesia donde se ospeden Para los Xpianos y que gocen de los bastimentos y géneros a la tasa del reyno y que las mercadurías despaña y Manila se devendan a los precios que pudieran sin ponerles pancada ni tasa.

- Que lo que al dcho Don Rodrigo se le a tratado de Parte de su Alteza de que desea que bengan mineros españoles a beneficiar los muchos Metales de plata que tiene en sus Reynos tiene Por dificultoso entablarlo Pero que tratará con el Rey D. Phelipe su señor que ynvíe ciento o ducientos con 
condición que de los tales sea la mitad de la plata que se sacare y de la otra mitad de haga dos partes Vna para su alteza el Emperador del Japón y otra para el Rey Don Phelipe su señor en todas las minas yncultas y no descubiertas sino que los españoles descubrieren por su conocimiento y yndustria en las minas ya labradas los dueños dellas harán concierto nubo con los dechos españoles y si fuere menester azogue lo traerán Pagándole acá por su justo balor y con él beneficiarán metales de oro.

- Que capitulado esto que será Tan ymportante cada Población de minas los mineros Xpianos tengan su sacerdote y se les diga missa y que allí aya persona puesta de parte de su alteza el emperador que cobre sus derechos y otra de parte del Rey Don Phelipe su sr y en todos estos Xpianos tengan juridición y mano para castigarlos el embajador despaña o capitán y en las naos que fueren de allá sus oficiales y ministros y que si algunos Xapones hicieren agravios algunos españoles luego losb mande su alteza castigar y si españoles le hicieren a los dechos japones serán exemplarmente castigados por sus cavezas y superiores.

- Que supuesto que el trato con espña es con el Mayor Monarca y señor del mundo y esta amistad cuadra y está tan bien aa estos Reynos del Japón, que su Alteza a de mandar luego despedir los Olandeses que éstos sólo bienen a Vrtar y rrobar y tienen sus provincias en lo postrero del mundo y no pudiendo ser útiles en éstas, Podrían hazer daño a las naos despaña y no se compadesen dos enemigos dentro de una casa ni será posible conservarse la amistad españa si esto no se pone luego en execución.

- Que los puertos todos se han de sondar y estar obligados los que biven en ellos a salir a meter las naos despaña que podrían benir derrotadas o con temporal y hacerles buena acogida y trato.

- Que todos estos capítulos se le a de dar al dcho Don Rodrigo de bivero chapa y provisión rreal con distinción y expresa declaración dellos Para que la llebe a España por tres duplicados y el dcho Don Rodrigo se obliga a tratarlo con el Rey su sr y enbiar dentro de dos años respuesta y resolución de todo adbirtiendo como adbierte a su alteza del dcho emperador que todos estos capítulos no asegura ni promete nada pues Vn basallo que está tan lejos de su Rey no sería justo que de lo que está por conceder y tan dudoso prometiese parte en lo que no la tiene solas estas advertencias an sido necesitado de ablarse en estos Reynos en la ocasión presente y no haver otra persona que pueda Poner en plática lo susodcho". 


\section{Anexo 2. Sobre detalles de las "Capitulaciones y asientos de Paz", traducidas por fray Luis Sotelo}

“- El gran señor de Japón pide al pde. Fray Luis Sotelo hable cosas a la Suprema Magestad.

- Viniendo navío de la nueva España al Japón, se le concede puerto donde le quisieren los españoles y sitios para que labren casas y vivan en la tierra.

- Iten. A los religiosos frayles se les consiente estar donde quisieren en todo Japón.

- Iten. Los navíos que van de luzón a la nueva españa, se les concede que tomen puerto en el Japón que inviernen y estén en él o q. Quisieren y aguarden tiempo para seguir su viaje, libremente cuando bien les estuviera.

- Iten. Se concede que cuando se quebrara o maltratara cuarquiera navío de las tierras del Rey y lo hubiere de renovar o fuere necessario aderezar los que anduuieren en la carrera o hacer otras de nueuo, se les dé todos los materiales, aderezo, gente y pertrechos necesarios, pasos, deniros y se mande rigurosamente se les den y vendan al precio común y corriente sin levantarle en nada.

- Iten. Cada y cuando que viniese despaña embaxador del Rey Don Philipe o de la nueva españa embaxador del Visorrey para asentar perpetuamente estas pazes y trato, será muy bien recibido y honrrado en todo como merese.

- Iten. Cuando fuera navío y mercaderes de Japón a Nueva España se les hará regalo y merced.

- Iten. Cuando viniese navío al Japón en las mercaderías y géneros que traxeren para el trato, Se juntarán los españoles y japoneses y se concertarán a su gusto entre sí mesmos para la venta y precio dellas ni que se les haga agravio ni fuerza ni injusticia alguna quedando libres y a su voluntad.

- Estas susodichas capitulaciones ofrece y consiente el Sr. De Japón y da su palabra de guardarlas y cumplirlas perpetuosamente sin quebrantar ninguna y embía de presente a Su Magestad tres cuerpos de armas y Un montante, y por su embajador a este padre Fray Luis Sotelo, para que las cosas menudas que estén en el corazón del emperador las trate y comunique de palabra de su parte a la Suprema Magestad". 